\title{
Research on China Industrial Structure Optimization Based on External Constraint
}

\author{
Hang Zhang \\ School of Economics and Management, Northwest University, 229 Taibai N. Rd. Xi'an, Shaanxi, \\ China710069
}

1535975895@qq.com

\begin{abstract}
Keywords: demand structure; resource structure; industrial structure optimization; external condition constraint; ecological environment
\end{abstract}

\begin{abstract}
The essence of industrial structure refers to the distribution structure of resources required in economic system operation in various industries. The industrial structure does not exist in isolation in the economic system. However, it is restrained by the external environment and is in the mutual relations of demand structure, ecological environment and resource structure. And it is an acknowledged fact that the per capita hold of resources of China is limited. So China's industrial structure optimization is facing increasingly constraint of the severe resource environment and the constraint of demand structure. Starting from the relationship between industrial structure and demand, ecology and resource, the test will seek for the systematic methods of China industrial structure optimization with the restrictions of external conditions, solve the problem of transformation of development mode scientifically and boost smooth and healthy development of national economy by constructing the planning models for four objective functions, involving economic growth, energy consumption reduction, pollution control and demand structure.
\end{abstract}

\section{Foreword}

The industrial structure is not isolated existing in the economic system but restrained by the external environment and it is in the mutual relations of demand structure, ecological environment and resource structure. Firstly, the industrial structure is restrained by the ecological environment. The industry scale and pollution load supported in a certain region are limited and the ecological environment in some regions is hard to be recovered once it is destroyed, which is bound to decrease the industrial efficiency greatly and influence the formation of local industrial structure; the industrial structure is influenced by the resource structure due to the resource input. Resource is a key factor for the regional development. The breadth, depth and reasonable degree of resource utilization can reflect the development standard of local economy directly, and can restrain the development speed of local economy. The industrial structure with reasonable resource utilization benefits the renewal of technology and enhances the utilization efficiency of resources; moreover, the improvement of the utilization efficiency of resources stands for a more reasonable industrial structure. The two factors affect each other and restrict one another; the product output makes the industrial structure correspond to the demand structure, which decides the guidance of demand structure relative to the industrial structure. Therefore, the industrial structure does not refer to one relation among industries simply, but refers to the structural relationship among industries in interaction with external environment, just shown as Fig. 1. 


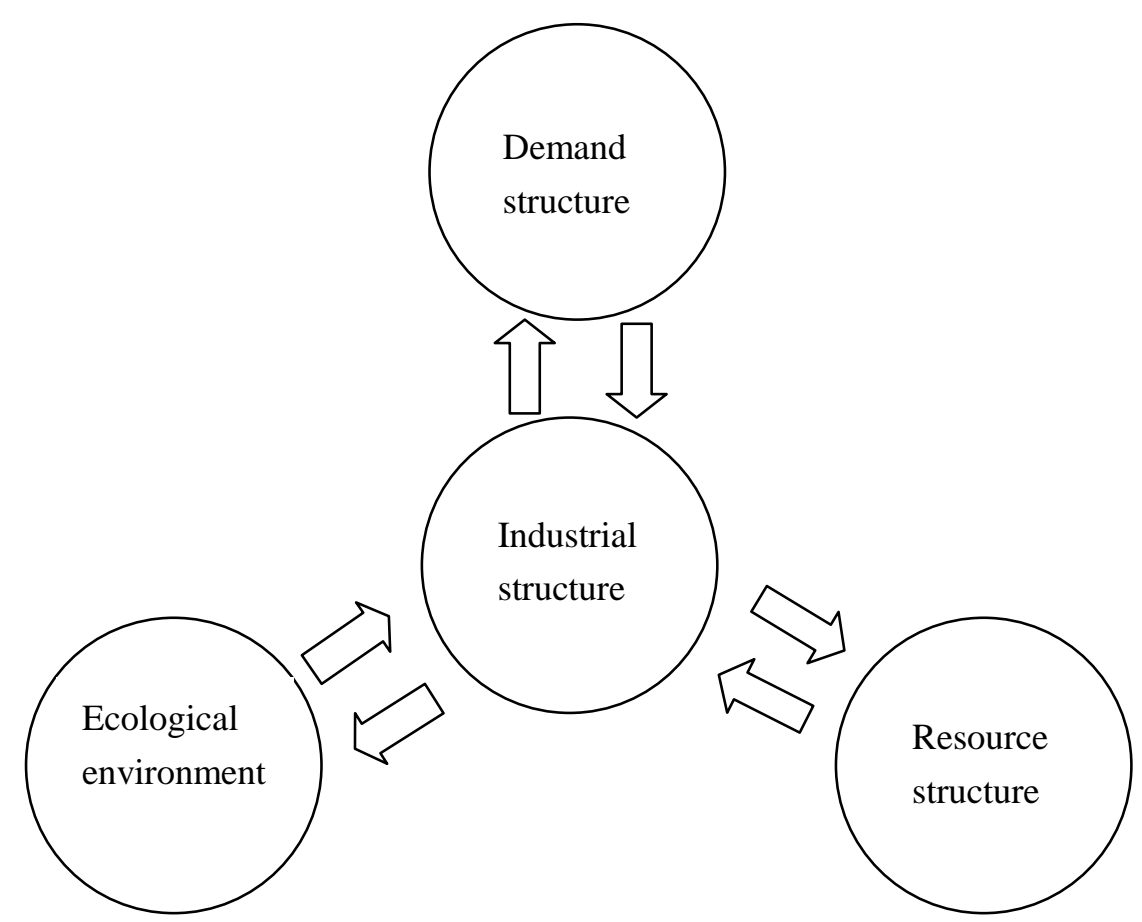

Figure 1. Interactive relationship diagram between industrial structure and external environment

\section{Interaction between Industrial Structure and External Environment}

\section{Industrial Structure and Demand Structure}

One of the important contents of industrial structure transformation is to alter the total demand structure of simulating economic growth. In recent years, the promoting function of three demands on China's economy has been extreme unbalance: the investment and net contribution rate of exports are relatively high, the contribution rate of consumption decreases and stays at a low level and the saving rate is higher than the world average. This deviates from the general trend of demand structure evolution. The demand structure of "high accumulation and low consumption" initially formed in China was closely related to the planned economy system. In early days of the new nation, China followed the Soviet Union to implement the "catching- up strategy" of heavy industry prior development and then the initial development mode of "high accumulation and low consumption" was formed. After the reform and opening-up, China experienced the rapid growth period lasting for over 30 years, but the demand structure of "high accumulation and low consumption" was not changed. After the Southeast Asia Financial Crisis in 1997, the shortage economy era of China ended, and the excess production capacity and demand constricted problem began. The demand structure of "high accumulation and low consumption" and extensive economic growth mode were confronted with changing. However, because of the lag social development, imperfect social security system and market-oriented reform in education, medical care and housing and other factors, the residents had strong intentions in precautionary saving, so the measures of expanding consumption demand did not make substantive advances. In 2001, China entered the WTO, which opened a huge foreign consumer market for the excess capacity, and some enterprises seized the chance to turn to the international market. The upgrading of the industrial structure was replaced by the market structure adjustment and the investment and export-oriented growth pattern was formed. In recent 10 years, this growth pattern has been strengthened gradually and the "investment and export dependence" in demand structure and "capital- oriented" phenomenon in income distribution were increasingly severe. China economy has entered a vicious circle of "fast increase of 
investment leading to excess production capacity, excess production capacity leading to more export and overabundant foreign exchange reserve and overabundant foreign exchange reserve leading to fast additional issuing of currency and leading to fast investment growth again". At the meantime, the capital always flows to places with revenue, so this demand structure is bound to make the industrial structure development lean to the capital intensive and other bulk commodity production industries, which will lead to excess production capacity. At the same time, the energy consumption was increased, the pollution was more serious and the vicious circle was formed because of the inherent lag in technology, low management efficiency and other problems. All in all, the initial problem to be solved in industrial structure optimization is the problem of demand structure and the problem of economic development mode transformation to increase of ratio of consumer demand in total demand.

After the international financial crisis broke out in 2008, the global economy entered in a new era of great revolution, great adjustment and great development and the acceleration in transformation of economic development patterns became the new theme of the times. We can see from the international environment that investment and deposit expansion in Europe and America and other developed countries, expansion of consumption in China and other emerging market countries and re-balance of global economy have been the new orientation of global evolution. We can see from the domestic situation that the "Demographic Dividend" supporting rapid growth of China economy for over 30 years begins to fade gradually and "Lewis Turning Point" of labor from infinite supply to relative shortage will appear. The traditional economic growth pattern will end up and it is urgent to construct a new consumption-oriented and innovation-driven development pattern with each passing day. Therefore, China has to change the current demand structure and then realizes transformation of development pattern and optimization of industrial structure.

\section{Industrial Structure and Ecological Environment and Resource Consumption.}

The industrial structure is a vital link connecting economic activities with ecological environment, and the industrial structure is closely related to the economic growth and environment pollution. Although the resource consumption and environment pollution involve different fields with different disposing methods, they are closely related in the actual economic activities. Hence, the optimization of industrial structure is critical to the quality and continuity of economic growth. During the process of economic growth, the contradiction between finiteness of natural resource supply and increasing demand and the contradiction between limited bearing capacity of environment and increasing pollutant discharge are increasingly acute. For example, the current structural contradictions in China industrial structure are acute. North China supplies heating in unity, so the ratio of industries with high energy consumption is large; the large state-owned enterprises are lag in restructuring and the enterprises focus on serving for the public; the government pays special attention to the livelihood issues. All these factors lead to low efficiency, severe pollution, high energy consumption, rapid increase of consumption of above-scale industrial comprehensive energy and low efficiency of energy utilization; what's more, the imperfect updated capacity exit mechanism leads to non- sustainable consumption of energy resources. The optimization of industrial structure under the double constraints of resource exploration and environment is of great significance with the multiple pressure and restrictions of lack of resources, shortage of energy and environment pollution.

\section{Industrial Structure Optimization Model Design under External Constraints}

\section{Establish objective function}

Combining the above analysis, we can design the objective function from four aspects: economic 
growth, demand structure optimization, resource consumption and pollution control. The ultimate goal of industrial structure optimization is to realize the growth of gross national product; one of the goals of the optimization is to realize maximum GDP; the measure of demand structure optimize is mainly based on the citizen consumption rate, which means the ratio of the total amount of a nation and an area used in citizen individual consumption and social consumption for a certain period to the gross national expenditures of the year or the amount of national income spent; with the constraints of resource environment, the industrial water consumption and industrial consumption for per 10 thousand yuan of GDP are the main factors in investigation of water benefit and energy consumption benefit, so the minimum consumption of water and maximum energy consumption benefit are the other main goals; the discharge of waste water, waste gas and waste residues is also the main indicator in measuring the discharge of pollutants of industrial enterprises. Decrease of the total emission amount of the waste water, waste gas and waste residues is of great significance of reducing stress on ecological environment.

Establish the modeling objective function as follows:

(1) Economic growth objective

$\max F(x n)=\sum a{ }^{*} x i(n)$

Take maximum economic growth as the objective. In the above function, ai is the value added ratio of $i$ industry and $x i(n)$ is the gross output of $n$ periods of $i$ industry.

(2) Resource consumption control objective

$\operatorname{minG}(\mathrm{xn})=\sum \operatorname{ci}(\mathrm{n}) * \mathrm{xi}(\mathrm{n})$;

$\operatorname{minH}(\mathrm{xn})=\sum \operatorname{di}(\mathrm{n}) * \mathrm{xi}(\mathrm{n})$

Take the minimum energy consumption as the objective to realize minimum industrial energy consumption for 10 thousand GDP and minimum industrial water consumption. In the above function, ci (n) is the energy consumption coefficient of gross output of each industry in n periods; di (n) is the water consumption coefficient of gross output of each industry in $n$ periods.

(3) Pollution control objective $\operatorname{minK}(\mathrm{xn})=\sum$ ei $(\mathrm{n}) * \mathrm{xi}(\mathrm{n})+\sum \mathrm{fi}(\mathrm{n}) * \mathrm{xi}(\mathrm{n})$

Take the minimum pollution as the objective and represent by chemical oxygen demand and minimum sulfur dioxide emissions by referring to related documents. In the function, ei (n) is the emission coefficient of chemical oxygen demand for $n$ years of $i$ industry and fi ( $n$ ) is the sulfur dioxide emission coefficient for $\mathrm{n}$ years in i industry.

(4) Demand structure optimization objective

$\operatorname{Max} \mathrm{Y}=\mathrm{R}$

Take the maximum consumption ratio in demand structure as the objective. Y refers to the demand structure index and $\mathrm{R}$ refers to the citizen consumption rate, which reflects the overall consumption level.

\section{Confirmation of constraint conditions}

(1) Industry scale constraint

Control the industrial development based on the industrial development planning and industrial growth rule.

(2) Energy constraint

$$
\sum \mathrm{ci}(\mathrm{n}) * \mathrm{xi}(\mathrm{n})<=\mathrm{R} 1 \text { (n) }
$$

$\mathrm{R} 1 \mathrm{n}$ ) is the maximum energy consumption constraint of each industry for $\mathrm{n}$ years.

(3) Water resource constraint

$\sum \operatorname{di}(\mathrm{n}) * \mathrm{xi}(\mathrm{n})<=\mathrm{R} 2$ (n)

$\mathrm{R} 2(\mathrm{n})$ is the maximum water consumption constraint of each industry for $n$ years. 
(4) Pollution control constraint

(1) Chemical oxygen demand emission constraint

$\sum$ fi (n)* xi (n) $<=$ R3 (n)

R3 (n) refers to the discharged total constraint of chemical oxygen demand in waste water discharge representation of each industry for $n$ years.

(2) Sulfur dioxide emission constraint

$\sum$ ei (n)* xi (n) $<=$ R4 (n)

R4 (n) refers to the discharged total constraint of sulfur dioxide in waste gas discharge representation of each industry for $\mathrm{n}$ years.

(5) Demand structure constraint

$\mathrm{R}>=\mathrm{R} 5$ (n)

$\mathrm{R} 5$ (n) refers to the citizen consumption rate in $n$ years.

\section{Confirmation of Data Sources}

The data required in the model are mainly calculated based on China Statistical Yearbook (20122013) and China Environment Statistical Bulletin (2012-2013). It places extra emphasis on estimating the industrial energy consumption, water consumption, pollution emission and industrial structure proportional relation of China from 2014 to 2015 based on the industrial structure optimization model which takes energy saving and environment protection as objectives. China tertiary industry development is confirmed as the optimization objective finally based on the different data statistical caliber and different difficulty of data collecting.

\section{Parameter Confirmation}

The value of China industrial structure change is mainly based on the 12th Five- year Plan Outline of National Economy and Social Development. During the 12th Five-year Plan period, the average annual gross domestic product increased by over $7 \%$; the outline indicated that the industrial structure was more reasonable, the development quality and standard of the tertiary industry were enhanced greatly and the average added value in service industry increased by over 4\% annually. Based on the 12th Five-year Plan Energy Saving and Emission Reduction Comprehensive Work Program, the energy consumption of energy saving and emission reduction index of composition for per 10 thousand yuan of GDP decreased by $16 \%$ to confirm the energy constraint dynamic control target. The specific parameters can be seen in Table 1. 
Table 1 Optimization Model R Value Confirmation

\begin{tabular}{|c|c|c|}
\hline Project & $\begin{array}{l}\text { Confirmatio } \\
\mathrm{n} \text { of } \mathrm{R} \text { Value }\end{array}$ & Remarks \\
\hline $\begin{array}{l}\text { Energy consumption } \\
\text { per } 10 \text { thousand yuan of } \\
\text { GDP (ton of standard coal) }\end{array}$ & {$[0,1.927]$} & $\begin{array}{l}\text { The energy consumption per } \\
10 \text { thousand yuan of GDP during } \\
\text { the 12th Five- year Plan period } \\
\text { decreased by } 10 \% \text {. }\end{array}$ \\
\hline $\begin{array}{l}\text { Water consumption in } \\
\text { primary industry }(100 \\
\text { million cubic meters })\end{array}$ & {$[0,495.96]$} & $\begin{array}{l}\text { The water consumption in the } \\
\text { primary industry during the } 12 \text { th } \\
\text { Five- year Plan period decreased by } \\
4 \% \text {. }\end{array}$ \\
\hline $\begin{array}{l}\text { Water consumption in } \\
\text { secondary industry }(100 \\
\text { million cubic meters })\end{array}$ & {$[13.5,14.17]$} & $\begin{array}{l}\text { The saved water in primary } \\
\text { industry is all used in the secondary } \\
\text { industry to confirm maximum. }\end{array}$ \\
\hline $\begin{array}{l}\text { Water consumption in } \\
\text { tertiary industry }(100 \\
\text { million cubic meters })\end{array}$ & {$[1.15,1.20]$} & $\begin{array}{l}\text { The saved water in primary } \\
\text { industry is all used in the tertiary } \\
\text { industry to confirm maximum. }\end{array}$ \\
\hline $\begin{array}{l}\text { Chemical oxygen } \\
\text { demand discharge }(10 \\
\text { thousand tons })\end{array}$ & {$[0,57]$} & $\begin{array}{l}\text { The emission during the } 12 \text { th } \\
\text { Five- year Plan period should be } \\
\text { controlled with the range of the } 11 \text { th } \\
\text { Five-year Plan. }\end{array}$ \\
\hline $\begin{array}{l}\quad \text { Sulfur } \\
\text { discharge } \quad(10 \text { thousand } \\
\text { tons })\end{array}$ & {$[0,63.3]$} & $\begin{array}{l}\text { The emission during the } 12 \text { th } \\
\text { Five- year Plan period should be } \\
\text { controlled with the range of the } 11 \text { th } \\
\text { Five-year Plan. }\end{array}$ \\
\hline $\begin{array}{l}\text { Citizen consumption } \\
\text { rate }(\%)\end{array}$ & {$[0,60]$} & $\begin{array}{l}\text { Refer to the global average } \\
\text { citizen consumption rate in } 2008 \text {. }\end{array}$ \\
\hline
\end{tabular}

\section{Program Analysis of China Industrial Structure Optimization Based on External Constraint}

The China industrial structure optimization under the constraint of external environment should not only achieve the objective of maximum economic growth, but also should achieve pollution emission control, increase of resource consumption efficiency, demand structure improvement and other multiple goals. The industrial structure optimization itself is a problem of constant coordination and constant servitization of tertiary industry, but the program of China industrial structure optimization under the external constraint gets its optimization program by taking the demand structure transformation as precondition and basis, taking energy saving, less environment pollution, ecological environment protection and improvement of environment self-repairing capability as the initial objectives and giving consideration to economic growth. Therefore, the tertiary industry optimization results are shown as Table 2 by taking industrial consumption per 10 thousand yuan of GDP and threshold value of pollution emission into consideration, by using the discussed calculation methods based on China energy saving and emission reduction requirements and constraint conditions and based on dynamic adjustment of planning year. 
Table 2 Energy saving and emission reduction program industrial structure optimization results form 2014 to 2015

\begin{tabular}{l|l|l}
\hline & 2014 & 2015 \\
\hline $\begin{array}{c}\text { Energy consumption } \\
\text { thousand tons of } \\
\text { standard coal) }\end{array}$ & 37.9 & 36.8 \\
\hline $\begin{array}{c}\text { Water consumption } \\
\text { million cubic meters) }\end{array}$ & 121 & 119 \\
\hline $\begin{array}{c}\text { Chemical oxygen } \\
\text { demand discharge (10 } \\
\text { thousand tons) }\end{array}$ & 23.26 & 22.38 \\
\hline $\begin{array}{c}\text { Sulfur } \\
\text { discharge (10 thousand } \\
\text { tons) }\end{array}$ & 2007 & 1999.6 \\
\hline $\begin{array}{c}\text { Proportion of the } \\
\text { primary industry (\%) }\end{array}$ & 9.8 & 9.7 \\
\hline $\begin{array}{c}\text { Proportion of the } \\
\text { second industry (\%) }\end{array}$ & 44.1 & 44.0 \\
\hline $\begin{array}{c}\text { Proportion of the } \\
\text { tertiary industry (\%) }\end{array}$ & 46.1 & 46.5 \\
\hline $\begin{array}{c}\text { Gross output (100 } \\
\text { million yuan) }\end{array}$ & 636130 & 680659 \\
\hline
\end{tabular}

To meet the requirements of energy saving and reduction of total emission of chemical oxygen demand and sulfur dioxide, China's oil processing, coking, chemical industry, steel, electricity and other industries with much energy consumption should focus on technology innovation and enhance the energy utilization efficiency. With this program, as the control of environment pollution sacrifices the economic growth in a certain degree, the gross output can not reach the increase goal of gross output in economic growth scheme. The gross GDP in 2015 was 68065.9 billion yuan which was lower than the gross output standard in economic growth scheme. We can see from the production value structure that the proportion of the primary industry is relatively low; the contribution of the secondary industry to the economic growth decreases slightly which indicates that the secondary industry plays a greater function in the economic growth of China; the contribution of the tertiary industry to the economic growth increases greatly which indicates that the strong development of the tertiary industry is beneficial to pollution control, and the inevitable requirement on pollution reduction is also the optimization of industrial structure. That is to say, only when the constant optimization of industrial structure is realized and the ecological income decreases can the economy realize growth with high quality.

\section{Conclusion}

As the acceleration of economic globalization and regional economic integration in the $21 \mathrm{st}$ century, the nations around the world start a new industrial structure upgrading and adjustment and the industrial structure is facing with higher tasks. During the process of economic development of China, the unreasonable industrial structure, low efficiency of energy resource utilization and fragile ecological environment caused by unreasonable demand structure are still acute. Adjusting 
and optimizing industrial structure and taking the sustainable development path are inevitable courses to realize the transformation of economic development mode and to overcome the bottleneck constraint of resource environment. On one hand, China must take the endogenous development strategic path to expand domestic demand, construct labor-oriented income distribution system, increase income for residents in middle and low classes and change the consumption pattern, and further optimize the demand structure and realize the fundamental goal of changing and influencing the industrial structure; on the other hand, China must take the sustainable development strategy to realize the coordination between sustainable economic development and sustainable resource and to realize the coordination between sustainable economic development and minimum environment pollution. It can create good conditions for the smooth and healthy development of social economy by taking the three conditions as the constraints of industrial structure upgrading and optimization.

\section{References}

[1] SHI Jinchuan, HUANG Lianghao; Aggregate Demand Structure Adjustment and Transformation of Economic Development Mode [J]; Economic Theory and Economic Management; the first edition of 2011

[2] SHI Qinghua, YANG Lei, HUANG Guangqing; Research on Industrial Structure Optimization Model under Resource Constraint Condition Based on Linear Planning Theory [J]; Technology Management Research; 2011 No. 12

[3] LI Yongyou; China Demand Structural Imbalance and Degree Evaluation [J] Economist; Jan. 2012

[4] LIU Shuru; Industrial Structure Rationalization Evaluation Index System Construction Research [J]; Science and Technology Management Research; 2011 (05)

[5] Written by T.E.Graedel.B.R.Allenby, translated by SHI Han; Industrial Ecology [M]; Tsinghua University Press; 2004

[6] Edited by SU Dongshui; Industrial Economics [M]; Higher Education Press; 2000

[7] China Industrial Structure Optimization Model and Analytical Research Based on Grey Variable Structure Control; FAN Decheng, ZHANG Wei [J]; Statistics and Information Forum; 2010. 25 (10)

[8] Value Network Reconstruction, Specification Evolution and Industrial Structure Optimization; LIU Mingyu, RUI Mingjie [J]; China Industrial Economy; 2012. (5)

[9] KONG Xiaohong; Circular Economy Development is an Effective Way for Industrial Structure Optimization--- Considerations on Anhui Industrial Structure Optimization and Adjustment [J]; Academic Circle; 2010 (02)

[10]PAN Bing; On Development of China Circular Economy and Existing Problems [J]; Modern Business; 2015 (36) 